\section{An Unusual Common Bile Duct Stricture after Cholecystectomy}

\begin{abstract}
A 75-year-old woman presented at an outside institution with cholestasis following a cholecystectomy procedure, which started laparoscopically but had to be switched to open surgery as a sealed perforation of the gallbladder was detected during the operation. Generally, the anatomical situation was described as very difficult.
\end{abstract}

Endoscopic retrograde cholangiopancreatography (ERCP), including endoscopic papillotomy (EPT), was carried out at the same institution, and showed a complete subhilar stenosis of the common bile duct. However, the proximal biliary tree was visualized by filling a fistula-like tract, which connected the intrahepatic biliary system with the common bile duct. An attempt to pass a flexible Terumo guide wire through the stricture failed, and attempts to achieve this led to a presumed guide-wire perforation.

The patient was then referred to our hospital, where we found the same anatomical situation on a repeat ERCP as described above (Figure 1). On attempts to pass the stricture, the guide wire seemingly perforated (Figure 2); but as it was used. Landshut, Germany
Figure 2 Guide-wire passage of the stenosis, with presumed perforation possible to follow the wire with a 6-Fr biliary bougie, we were able to fill the proximal biliary system. Access was then secured using balloon dilatation (Figure 3) and stenting with two 7-Fr plastic stents. The usual procedure was then followed, aiming to achieve placement of at least two 10-Fr stents [1] and stents in situ with scheduled exchanges every 3 months for about 12 months, in order to obtain a long-term dilatation effect [2].

We consider this case to be peculiar in two ways: firstly, a fistula-like tract contributed to maintenance of bile flow, bypassing a complete subhilar obstruction (Figure 1). Secondly, the course of the guide wire was seemingly outside of the biliary tract (Figure 2), but this was probably due to imaging artifacts and the fact that only anteroposterior fluoroscopy was

\section{P. Born ${ }^{1}$, F. Käser ${ }^{2}$, T. Rösch ${ }^{1}$}

${ }^{1}$ Dept. of Medicine II, Rechts der Isar Hospital, Technical University of Munich, Munich, Germany

${ }^{2}$ Dept. of Internal Medicine, District Hospital of Landshut-Achdorf,
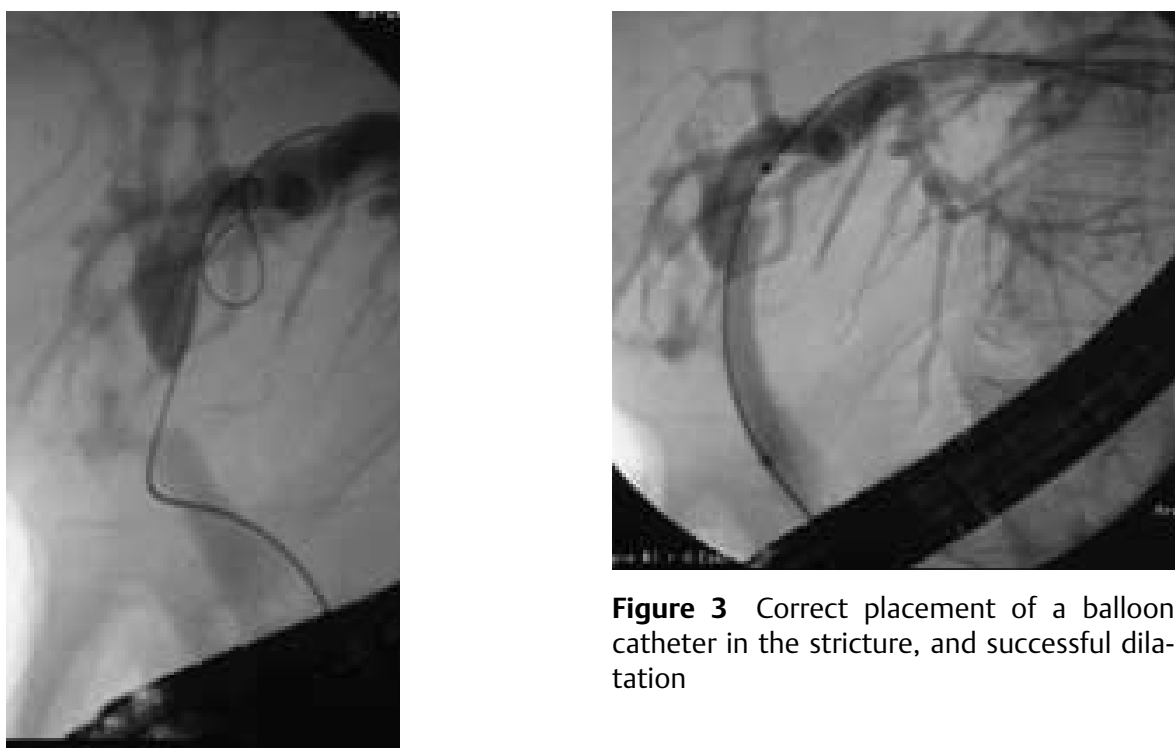

Figure 3 Correct placement of a balloon catheter in the stricture, and successful dilatation

\section{References}

${ }^{1}$ Costamagna G, Pandolfi M, Mutignani $\mathrm{M}$ et al. Long-term results of endoscopic management of postoperative bile duct strictures with increasing numbers of stents. Gastrointest Endosc 2001; 54: $162-168$

${ }^{2}$ Born P, Rösch T, Brühl K et al. Outcome of endoscopic and percutaneous transhepatic treatment of benign biliary strictures. Endoscopy 1999; 31: 725 731

\section{Corresponding Author}

\section{P. Born, M.D.}

II. Med. Klinik

Klinikum rechts der Isar

Technische Universität München Ismaningerstrasse 25

81675 München

Germany

Fax: +49-89-4140-4905

E-mail: peter.born@lrz.tumuenchen.de
Figure 1 Subhilar stenosis of the common bile duct, with the intrahepatic biliary ducts and the common bile duct 